\title{
Indigenous peoples, local communities and climate change mitigation
}

\author{
Ameyali Ramos-Castillo ${ }^{1} \cdot$ Edwin J. Castellanos ${ }^{2}$ • \\ Kirsty Galloway McLean ${ }^{3}$
}

Received: 29 August 2016 / Accepted: 11 October 2016/Published online: 2 January 2017

(C) Springer Science+Business Media Dordrecht 2016

This special issue of Climatic Change collects recent findings on the relationship between climate change mitigation and local communities/Indigenous peoples in a single issue. Specifically, this issue seeks to address the question of what policy measures have proven effective and in what context for advancing both the goals of indigenous sovereignty and climate change mitigation. The journal aims to provide a means of exchange among those working in different disciplines on problems related to climatic variations and to provide a platform to reflect on the wide and diverse range of perspectives and experiences concerning Indigenous peoples and local communities and climate change mitigation responses. Although many papers are available regarding the contributions and impacts of climate change adaptation and Indigenous peoples, significantly less material is available regarding their relationship and contributions to climate change mitigation. The papers in this special issue address some of the most pertinent cross-disciplinary topics facing policy-makers today, including links between mitigation initiatives, livelihoods, and resilience, and how these impact local, regional and international levels.

This article is part of a Special Issue on "Climate Change Mitigation and Adaptation with Local Communities and Indigenous Peoples" edited by Kirsty Galloway McLean, Ameyali Ramos Castillo, Edwin Castellanos, and Aqqaluk Lynge.

Ameyali Ramos-Castillo aramoscastillo@gmail.com

Edwin J. Castellanos ecastell@uvg.edu.gt

Kirsty Galloway McLean

kirsty@biochimera.com

1 United Nations University - Institute for the Advanced Study of Sustainability, Tokyo, Japan

2 Center for Environmental and Biodiversity Studies, Universidad del Valle de Guatemala, Guatemala City, Guatemala

3 BioChimera, Melbourne, Australia 
Indigenous peoples and their traditional knowledge have an important role to play in responding to climate change. Indigenous peoples form approximately $5 \%$ of the world's population, manage $11 \%$ of the world's forest lands and customarily own, occupy or use somewhere between 22 and 65\% of the world's land surface (UNDP 2011; RRI 2015). It has been estimated that indigenous lands and other protected areas created to safeguard land rights, indigenous livelihoods, biodiversity and other values contain more than 312 billion tons of carbon (Campbell et al. 2008). Recent analyses reveal that indigenous territories in the Amazon Basin, the Mesoamerican region, the Democratic Republic of Congo and Indonesia alone contain more than $20 \%$ of the carbon stored aboveground across the whole planet (AMPB et al. 2015).

Despite having contributed the least to global warming by traditionally leading 'low carbon' ways of life, Indigenous peoples and local communities are disproportionately vulnerable to climate change because: 1 . They often live in ecosystems particularly prone to the effects of climate change (polar regions, small islands, mountain regions, humid tropics, coastal regions, deserts); 2 . They are heavily dependent on lands and resources for basic needs and livelihoods (food, medicine, shelter, fuel, etc.); and 3. They are among the poorest and most marginalized people globally. Compounding these vulnerabilities, programs being implemented by non-indigenous people to mitigate and adapt to climate change also have the potential to adversely affect the livelihoods of IP as well as undermine their customary rights to lands and natural resources if not properly designed and implemented (Nilsson 2008). Examples of such a situation are the complaints about appropriation of indigenous lands in various regions in Latin America to establish oil palm plantations for biofuel production. The Mapuche people in Chile, for example, have repeatedly complained against the establishment of forestry companies in their lands claiming that the forest plantations dry their lands and pollute their waters with chemicals (Reinao 2008).

However, Indigenous peoples are not simply victims of climate change: they have an important contribution to make to address climate change. Due to their close relationship with their environment they are repositories of learning and knowledge on successfully coping with local-level climate variability and effectively responding to major environmental changes such as natural disasters. Indigenous peoples play a fundamental role in the conservation of biological diversity and the protection of forests and other natural resources; their traditional knowledge on climate variability can also enrich substantively scientific knowledge and adaptation activities of others. The detailed knowledge of Inuit and Sami of snow and ice regimes and the knowledge of Pacific Islanders of ocean currents, winds and tides in relation to anticipating extreme weather are just two well-documented examples of traditional knowledge applied to weather forecasting. Case studies in diverse locations such as China, Kenya and the Bolivian Andes show that the use and knowledge of traditional crop varieties is essential for adaptation to unpredictable weather (Nakashima et al. 2012).

Several themes unite the papers in this special issue. First and foremost, they highlight that Indigenous peoples, local communities and climate change mitigation are inherently and dynamically linked - mitigation initiatives that are being proposed today have implications not only for the climate, but also for the livelihoods and the nature of choices that will be available to Indigenous peoples and local communities in the future. Recent advances in data availability, theoretical models and empirical methods make it increasingly possible to identify strategies and frameworks that will benefit both climate mitigation and Indigenous peoples.

A second uniting theme is that strategies that support both the increased resilience of Indigenous peoples, local communities and the mitigation of climate change can also provide economic and livelihood benefits for indigenous and local communities. 
Thirdly, these papers demonstrate that Indigenous and local peoples have a critical role to play in successful mitigation efforts. Even if sweeping global climate change agreements like the recently adopted Paris Agreement (UNFCCC 2015) are successfully implemented, present global responses to climate change will ultimately fail unless they are grounded in the recognition of Indigenous peoples and local communities rights to land, territory, and livelihood.

The first paper in the series by Thornton and Comberti reviews development policy and highlights the importance of improved synergies between mitigation and adaption strategies. Case studies from communities in Alaska and Nepal illustrate current and potential synergies and trade-offs and how these might be harnessed to maximize beneficial outcomes. Brugnach et al. then analyze how issues of scale, knowledge and power interrelate as a barrier or opportunity for the involvement of indigenous groups in mitigation measures. They suggest that multiscalar negotiations, blended knowledge and power-sharing structures are necessary to include indigenous communities as valuable partners in climate mitigation. From here, Alteri and Nicholls explore how three key traditional agroecological strategies (biodiversification, soil management and water harvesting) can be implemented in the design and management of agroecosystems allowing farmers to adapt to climate change. This strategy both increases resilience and provides economic benefits, including mitigation of climate change. Likewise, Russell-Smith et al. demonstrate how Australian Aboriginal people have commercially benefited from community-based savanna burning emissions reduction projects grounded in traditional fire knowledge. They then explore how these methodologies could be implemented in other continental savanna settings in Namibia and Venezuela. At a more local scale, Berrueta et al. provide a case study of how improved cookstoves have been identified in Mexico as a key opportunity to advance sustainable local development priorities in disadvantaged regions while mitigating climate change. Sanchez and Izzo explore the dual contribution of micro hydropower in local communities in the Dominican Republic to both climate change mitigation as well as enhancing adaptive capacity through increased biodiversity protection and improved wellbeing. Vierros takes us back to the international scale with an in-depth analysis of the potential of carbon market mechanisms for those conserving blue carbon ecosystems. She explains how blue carbon management could serve as a platform for collaboration between Indigenous peoples and climate change and biodiversity practitioners.

This special issue offers an approach that considers Indigenous peoples and local communities as important stakeholders and agents in climate mitigation responses. It seeks to spark dialogue and understanding among different actors to consider a pivotal shift where the active involvement of Indigenous peoples and local communities in the development of climate mitigation alternatives becomes a basis for cross-disciplinary collaboration and shared governance of climate mitigation solutions.

Finally, the editors of this special issue would like to thank the contributing authors who made this publication possible, the communities and individuals that so generously shared their knowledge and experiences and inspired the work, and the editors of Climatic Change journal-especially Kristin Kuntz-Duriseti-for their tireless support throughout the publication process.

\section{References}

AMPB, COICA, AMAN, REPALEAC, Woods Hole, EDF (2015) Tropical forest carbon in indigenous territories: a global analysis. Available at: https://www.edf.org/sites/default/files/tropicalforest-carbon-inindigenous-territories-a-global-analysis.pdf 
Campbell A, Miles L, Lysenko I, Hughes A, Gibbs H (2008) Carbon storage in protected areas: technical report. UNEP World Conservation Monitoring Centre

Nakashima D, Galloway McLean K, Thulstrup H, Ramos A, Rubis J (2012) Weathering uncertainty: traditional knowledge for climate change assessment and adaptation. Paris, UNESCO and Darwin, UNU, p. 120

Nilsson C (2008) Climate change from an indigenous perspective: key issues and challenges. Indigenous affairs, climate change and indigenous peoples, 1-2/08. IWGIA, Copenhagen, pp 8-15

Reinao R (2008) The Mapuche and climate change in the Chilean neoliberal economic system. Indigenous affairs, climate change and indigenous Peoples, 1-2/08. IWGIA, Copenhagen, pp 66-71

RRI (Rights and Resources Initiative) (2015) Who Owns the World's Land? A global baseline of formally recognized indigenous and community land rights. RRI, Washington, DC

UNDP (United Nations Development Programme) (2011) Human Development Report 2011: Sustainability and Equity - A Better Future for All. Palgrave Macmillan, New York

UNFCCC (United Nations Framework Convention on Climate Change) (2015) Adoption of the Paris Agreement, 21st Conference of the Parties. United Nations, Paris 